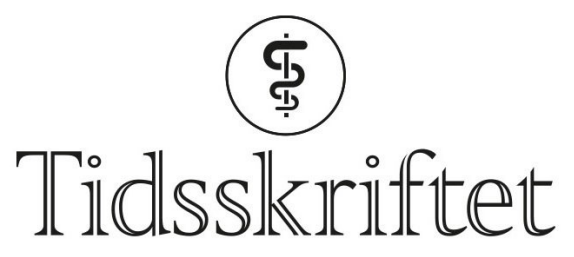

DEN NORSKE LEGEFORENING

\title{
Pasientrapportert livskvalitet ved fedme - utvikling av nytt måleinstrument
}

ORIGINALARTIKKEL

ANNY AASPRANG

E-post:annyaa@hvl.no

Institutt for helse og omsorgsvitskap, Campus Førde

Høgskulen på Vestlandet

og

Senter for helseforsking

Helse Førde

Ho har bidratt med ide, utforming, datainnsamling, analyse og tolking av data samt utarbeiding av sjølve manuset.

Anny Aasprang er ph.d. og sykepleier.

Forfatteren har fylt ut ICMJE-skjemaet og oppgir ingen interessekonflikter.

\section{VILLY VÅGE}

Haraldsplass diakonale sykehus

og

Senter for helseforsking

Helse Førde

Han har bidratt med datainnsamling, revisjon av manus og godkjenning av innsendt manus.

Villy Våge er overlege/kirurg og leder for Norsk kvalitetsregister for fedmekirurgi (SOReg-N).

Forfatteren har fylt ut ICMJE-skjemaet og oppgir ingen interessekonflikter.

\section{TONE NYGARD FLØLO}

Global helse og samfunnsmedisin

Universitetet i Bergen

Ho har bidratt med datainnsamling, revisjon av manus og godkjenning av innsendt manus.

Tone Nygard Flølo er sykepleier og ph.d.-stipendiat.

Forfatteren har fylt ut ICMJE-skjemaet og oppgir ingen interessekonflikter.

\section{PÅL ANDRE HEGLAND}

Institutt for helse- og omsorgsvitskap, Campus Førde

Høgskulen på Vestlandet

Han har bidratt med revisjon og godkjenning av manus.

Pål Andre Hegland er intensivsykepleier og ph.d.-stipendiat ved Universitetet i Bergen.

Forfatteren har fylt ut ICMJE-skjemaet og oppgir ingen interessekonflikter.

\section{RONETTE KOLOTKIN}

Department of Community and Family Medicine

Duke University School of Medicine

Durham 
Institutt for helse og omsorgsvitskap,Campus Førde

Høgskulen på Vestlandet

Ho har bidratt med analyse og tolking av data.

Ronette Kolotkin er psykolog og professor.

Forfatteren har fylt ut ICMJE-skjemaet og oppgir ingen interessekonflikter.

\section{GERD KARIN NATVIG}

Global helse og samfunnsmedisin

Universitetet i Bergen

Ho har bidratt med revisjon og godkjenning av manusversjonen.

Gerd Karin Natvig er tidligere professor.

Forfatteren har fylt ut ICMJE-skjemaet og oppgir ingen interessekonflikter.

\section{JOHN ROGER ANDERSEN}

Institutt for helse- og omsorgsvitskap, Campus Førde

Høgskulen på Vestlandet

og

Senter for helseforsking

Helse Førde

Han har bidratt med ide, utforming, analyse og tolking av data, revisjon og godkjenning av manusversjon

John Roger Andersen er professor ved Høgskulen på Vestlandet.

Forfatteren har fylt ut ICMJE-skjemaet og oppgir ingen interessekonflikter.

\section{BAKGRUNN}

Mange skjemaer for måling av livskvalitet for pasienter med fedme krever omfattende utregning før bruk. Det er behov for skjemaer der svarene enkelt kan vurderes under pasientsamtalen. Vi har utviklet skjemaet Patient Reported Outcomes in Obesity (PROS). Målet med studien var å teste skjemaets reliabilitet og validitet.

\section{MATERIALE OG METODE}

Skjemaet ble brukt for å spørre pasienter om i hvilken grad vekt eller kroppsform ble opplevd som plagsom. En gruppe pasienter med gjennomsnittlig kroppsmasseindeks (BMI) på $42(n=109)$ fylte ut PROS-skjemaet og The Impact of Weight Quality of Life questionnaire (IWQOL-Lite) før fedmeoperasjon. En annen gruppe med gjennomsnittlig BMI på 29 (n = 95) fylte ut PROS-skjema 1-5 år etter fedmeoperasjon. $68 \%$ av pasientene var $>40$ år og $79 \%$ var kvinner. Vi benyttet Cronbachs alfa, faktoranalyse, Spearmans rangtest og uavhengig t-test $\mathrm{i}$ den statistiske analysen.

\section{RESULTATER}

Cronbachs alfa for PROS-totalskår var 0,90, og faktoranalysen viste en tydelig faktor (egenverdi $=4,7)$ som forklarte $58,4 \%$ av variasjonen. Korrelasjon for test-retest var $0,93(\mathrm{p}<$ o,o01). Korrelasjonskoeffisientene mellom PROS-skår, IWQOL-Lite-totalskår $\left(r_{s}=-0,91\right)$ og kroppsmasseindeks $\left(r_{s}=0,60\right)$ var signifikante $(p<0,001)$. T-test viste effektstørrelse (forskjell i standardavvik) mellom ikke-operert og operert gruppe på 1,9 (95 \% KI 1,6-2,5) for PROS-skjemaet og 2,1 (95\% KI 1,7-2,5) for IWQOL-Lite-totalskår.

\section{FORTOLKNING}

PROS-skjemaet er et reliabelt og valid skjema for måling av fedmespesifikk livskvalitet.

Pasienter med alvorlig fedme har ofte lav helserelatert livskvalitet (1). Å bedre denne er 
derfor et viktig mål i behandlingen (2). Selv om de fleste pasienter opplever bedring av livskvalitet etter fedmekirurgi, opplever enkelte pasienter med lite vekttap og/eller mye bivirkninger en forverring $(3,4)$. Noen pasienter opplever symptomer på angst og depresjon uavhengig av vektendring (5). Oppfølging av pasienters psykiske helse etter fedmekirurgi er ikke standardisert (6).

Det finnes ingen universell definisjon av livskvalitet, men begrepet forstås ofte som uttrykk for subjektiv opplevelse av velvære (7). Begrepet brukes på flere måter, og i norsk sammenheng er det vanlig å bruke det som en betegnelse på hvordan livet oppleves for den enkelte. Ved måling av livskvalitet blir det ofte referert til fysisk helse og funksjon, psykisk helse, sosiale relasjoner og økonomisk status (8).

Både generiske og sykdomsspesifikke skjemaer blir benyttet for å vurdere belastningen av fedme $(9,10)$, og de siste tiårene er det utviklet flere sykdomsspesifikke livskvalitetsskjemaer for fedme (11). Mange av skjemaene er utviklet for forskning og krever ofte omfattende utregning. Vi har sett et behov for skjemaer med få spørsmål som kan brukes i pasientsamtalen, og har utviklet et fedmespesifikt livskvalitetsskjema, Patient Reported Outcomes in Obesity (PROS) i samarbeid med klinikere og pasienter. Dette skal kunne brukes både i forskning og i klinisk praksis. Formålet med denne studien var å teste skjemaets reliabilitet og validitet.

\section{Materiale og metode}

Vi gjorde en tverrsnittsstudie blant pasienter som hadde fått utført fedmeoperasjon (vertikal ventrikkelreseksjon) ett til fem år tidligere $(n=95)$ eller som stod på venteliste for fedmeoperasjon $(n=109$ ). Denne utvalgsstørrelsen gjorde det mulig å oppdage en statistisk signifikant, men liten korrelasjon ( $\mathrm{r}=0,22)$, og en statistisk signifikant, men liten standardisert forskjell i skår mellom grupper målt med en uavhengig t-test ( 0,41 ; gitt pverdi $=0,05$ og styrke $=0,90$ ). Alle som oppfylte inklusjonskriteriene fikk forespørsel om å delta i studien da de møtte på informasjonsmøte eller kontroll ved fedmepoliklinikken ved Førde sentralsjukehus og på Voss sjukehus. Data ble samlet inn i perioden august 2015 til mars 2016. Kriteriene for å delta i studien var at pasientene var fedmeoperert eller oppfylte kriteriene for kirurgisk behandling av fedme.

Det var ingen kontakt mellom forsker og pasient under datainnsamlingen. Spørreskjemaene ble utlevert på poliklinikken sammen med skriftlig invitasjon med informasjon om studien. Returnering av utfylt spørreskjema ble regnet som samtykke til deltakelse. Vi brukte Norsk senter for forskningsdatas sjekkliste til å vurdere om studien var meldepliktig. Alle spørsmålene i sjekklisten ble besvart med «nei». Forskningsetiske retningslinjer ble fulgt, og ettersom studien var anonym, vurderte vi den som ikke meldepliktig til personvernombudet eller etisk komité.

\section{MÅLEINSTRUMENTER}

I PROS-skjemaet blir pasientene spurt om i hvilken grad vekt eller kroppsform oppleves som plagsom innenfor følgende områder: fysisk aktivitet, smerter, diskriminering, søvn, seksualliv, sosial omgang, arbeid/skole og selvfølelse. Skjemaet har fire mulige svaralternativ: ikke plaget (o), mildt plaget (1), moderat plaget (2) og betydelig plaget (3). Pasientene blir bedt om å krysse av for det alternativet som passet best i dagens situasjon (appendiks 1).

Skjemaet ble utviklet gjennom et samarbeid mellom pasienter, klinikere og forskere og kan defineres som en indikator på livskvalitet, eller mer spesifikt: fedmerelatert livskvalitet. Skjemaet er rettet mot grad av plager eller fravær av plager og ikke mot "positive helseaspekter». Både totalskår og delskår kan brukes. Totalskår skal brukes som en indikator for hvor plaget pasienten er og regnes ut som gjennomsnittsverdi ved å summere delspørsmålene og dividere med antall svar. Minimum fem spørsmål må være besvart. Tentativt definerte grenseverdier indikerer $<0,5$ som ingen plager, 0,5-1,49 som milde plager, 1,5-2,49 som moderate plager og $\geq 2,5$ som betydelige plager. Totalskår alene skal 
ikke brukes i klinisk arbeid, siden en pasient kan ha lav totalskår, men likevel betydelige plager på enkeltområder.

Skjemaet The Impact of Weight on Quality of Life Questionnaire short-form (IWQOL-Lite) er et validert, selvrapportert livskvalitetsskjema for vurdering av fedmespesifikk livskvalitet (12). Dette blir regnet som gullstandarden for å måle livskvalitet hos denne pasientgruppen. Her vurderes kroppsvektens betydning innenfor områdene fysisk funksjonsevne, selvbilde, seksualliv, offentlig belastning og arbeid. Skjemaet kan oppsummeres med en totalskår eller med en sumskår for hvert av de fem områdene som er transformert til en skala o-10o. Høy skår indikerer høy fedmespesifikk livskvalitet (12). Skjemaet er validert for norske forhold (13).

\section{PILOTSTUDIE}

Vi testet spørreskjemaet i en pilotstudie på 17 personer som var på informasjonsmøte før operasjon. Vi spurte «i hvilken grad de hadde problemer med vekt eller kroppsform». Etter tilbakemelding fra pasientene ble spørsmålsstillingen endret til «i hvilken grad vekt eller kroppsform oppleves som plagsom». Deretter ble skjemaet testet i en ny pilotstudie i tre grupper med til sammen 54 personer: to grupper som var på informasjonsmøte før operasjon (39 pasienter) og én gruppe som var på oppdateringskurs to år etter operasjon (15 pasienter). Det ble deretter utført retesting av skjemaet på slutten av kursdagen. 26 pasienter fylte da ut skjemaet. Pasientene evaluerte spørreskjemaet skriftlig og gjennom deltakelse i gruppeintervju ledet av prosjektansvarlig. Pasientene $(n=54)$ rapporterte at alle spørsmål og svarkategorier var enkle å forstå på den siste pilotstudien.

\section{STATISTISK ANALYSE}

Deskriptiv statistikk ble benyttet for å beskrive kliniske og sosiodemografiske karakteristika og blir presentert som prosent eller gjennomsnitt med standardavvik (SD). Fordi dette er en valideringsstudie, brukte vi kun skår på PROS- og IWQOL-Lite-skjemaene som var basert på komplette utfyllinger.

Intern konsistens ble målt ved å beregne Cronbachs alfa, og en verdi over o,7 ble ansett som tilfredsstillende (14). Cronbachs alfa ble beregnet også når et spørsmål ble holdt utenfor. I tillegg korrelerte vi hvert enkeltspørsmål med totalskåren i PROS-skjemaet og korrigerte for overlapp. For å undersøke om totalskåren var stabil når den ble fylt ut av samme pasient med fem timers mellomrom, ble en test-retest-analyse benyttet ved hjelp av Spearmans rangtest. En korrelasjonskoeffisient $>0,7$ er anbefalt, mens verdier $>0,85$ er ideelt (15).

Prinsipal komponentanalyse ble benyttet for å undersøke konstruksjonsvaliditet, altså om spørsmålene i PROS-skjemaet utgjorde en totalskår eller flere skårer. En komponent med egenverdi $\geq_{1}$ ble regnet som indikasjon på en selvstendig skår. Forklart variasjon for en komponent med egenverdi $\geq 1$ skal rapporteres, og faktorladninger på enkeltspørsmål i en skår > o,40 er akseptable (16). Vi testet kriterievaliditet, altså ny skår mot gullstandard som skal måle det samme, ved å korrelere totalskåren for PROS-skjemaet med totalskåren for IWQOL-Lite-skjemaet ved hjelp av Spearmans rangtest. En korrelasjonskoeffisient $>0,7 \mathrm{er}$ anbefalt, mens verdier $>0,85$ er ideelt (15). Vi undersøkte konvergerende validitet, altså om PROS-totalskår og -delspørsmål var korrelert med variabler som ikke er det samme, men som teoretisk sett skal være relatert til PROS-skjemaet.

Korrelasjonskoeffisienter for konvergerende validitet ble tolket slik: > 0,5 var stor, o,3-0,49 moderat, o,1-0,29 liten og < 0,1 ubetydelig effektstørrelse (14). Gulv- og takeffekter, de som skårer lavest og høyest mulig, er presentert og bør være under $15 \%$ (17).

Alle analyser så langt er basert på at ikke-opererte og opererte pasienter er slått sammen til én gruppe. Stratifiserte analyser finnes i appendiks 2 (NB! Tabellene i appendiks 2 har ikke blitt fagfellevurdert, redaksjonens anmerkning.) Uavhengig t-test ble brukt for å sammenligne gruppene (operert versus ikke-operert). Effektstørrelse ble beregnet ved å kalkulere forskjellen mellom gjennomsnittlig PROS-skår for den opererte og den ikke- 
opererte gruppen dividert, med samlet standardavvik $\sqrt{\left[\frac{S D_{1}^{2}+S D_{2}^{2}}{2}\right]}$. Som terskler på effektstørrelse brukte vi o,2 (liten), o,5 (moderat) og o,8 eller mer (stor) (14).

Statistiske analyser ble utført med GPower 3.1.9.3 og Statistical Package for Social Sciences for Windows (SPSS), versjon 24.o (Chicago, IL). En tosidig $\mathrm{p}<0,05$ ble satt som nivå for statistisk signifikans.

\section{Resultater}

Totalt 204 av 210 (97\%) pasienter takket ja til å delta i studien. Pasientkarakteristika er presentert i tabell 1. Alle pasientene fylte ut PROS-skjemaet komplett, mens for IWQOL-Liteskjemaet varierte det innen de fem områdene ( $78-96 \%$ ).

\section{Tabell 1}

Karakteristika ved inkluderte pasienter $(\mathrm{n}=204)$ som hadde fătt utført fedmeoperasjon $(\mathrm{n}=$ 95), eller som stod på venteliste for fedmeoperasjon $(n=109)$ ved sykehusene i Førde eller Voss august 2015-mars 2016. Antall (\%) dersom annet ikke er angitt.

\begin{tabular}{|c|c|c|c|}
\hline Karakteristika $^{1}$ & Alle & Ikke-opererte & Opererte \\
\hline \multicolumn{4}{|l|}{ Alder } \\
\hline$<30$ år & $23(11,3)$ & $12(11,0)$ & $11(11,6)$ \\
\hline 30-39 år & $43(21,1)$ & $26(23,9)$ & $17(17,9)$ \\
\hline $40-49$ år & $63(30,9)$ & $39(35,8)$ & $24(25,3)$ \\
\hline $50-59$ år & $55(27,0)$ & $24(22,0)$ & $31(32,6)$ \\
\hline$>50$ år & $20(9,8)$ & $8(7,3)$ & $12(12,6)$ \\
\hline Kjønn, kvinner & $157(77,0)$ & $82(75,2)$ & $75(78,9)$ \\
\hline BMI $\left(\mathrm{kg} / \mathrm{m}^{2}\right)$, utgangsverdi, gjennomsnitt $\pm \mathrm{SD}$ & & $41,7 \pm 5,2$ & $29,4 \pm 4,9$ \\
\hline \multicolumn{4}{|l|}{ Sivilstatus } \\
\hline Gift/samboer & $143(70,4)$ & $76(70,4)$ & $67(70,5)$ \\
\hline Enslig & $60(29,6)$ & $32(29,6)$ & $28(29,5)$ \\
\hline \multicolumn{4}{|l|}{ Utdanning } \\
\hline Grunnskole & $34(16,8)$ & $25(22,9)$ & $9(9,7)$ \\
\hline Videregående skole & $117(57,9)$ & $56(51,4)$ & $61(65,6)$ \\
\hline Universitetsutdanning $\leq 4$ år & $43(21,3)$ & $23(21,1)$ & $20(21,5)$ \\
\hline Universitetsutdanning $\geq 4$ år & $8(4,0)$ & $5(4,6)$ & $3(3,2)$ \\
\hline
\end{tabular}

${ }^{1}$ Pasienttallene varierte fra 200 til 204 for de ulike variablene.

Cronbachs alfa for PROS-totalskår var 0,90. Dersom ett spørsmål ble holdt utenfor, var Cronbachs alfa o,88-o,89. Item-total-korrelasjonen, korrigert for overlapp, var o,57-0,75. Test-retest for PROS-skjemaet var o,93 ( $\mathrm{p}<0,001)$. Prinsipal komponentanalyse viste at én enkeltfaktor forklarte $58,4 \%$ av variasjonen i skjemaet. Faktorladningen viste høy homogenitet og varierte fra o,66 til o,83. Kommunaliteten var o,43-0,69 (tabell 2). I PROSskjemaet skåret $2 \%$ av pasientene i ikke-operert gruppe på lavest mulig nivå (gulveffekt), mot 28 \% i operert gruppe. På høyest mulig nivå (takeffekt) skåret 4 \% i ikke-operert gruppe, mot 1 \% i operert gruppe. Korrelasjonskoeffisientene mellom PROS-, IWQOL-Lite-totalskår og BMI var statistisk signifikante ( $\mathrm{p}<0,001$ ) og i forventet retning og størrelse (tabell 3 ). Da vi gjorde stratifiserte analyser for ikke-operert og operert gruppe, fant vi generelt sett lignende, men noe svakere assosiasjoner enn i hele utvalget, samt en mulig tofaktormodell for PROS-skjemaet (appendiks 2). T-test viser høy sensitivitet for gruppeforskjeller, og effektstørrelsen mellom ikke-operert og operert gruppe var 1,9 (95\% KI 1,6-2,5) for PROStotalskår og 2,1 for IWQOL-Lite-totalskår ( $95 \%$ KI 1,7-2,5). Ellers er effektstørrelse for de ulike enkeltspørsmålene i PROS mellom operert og ikke-operert gruppe oppgitt som prosent 
(tabell 4).

\section{Tabell 2}

Reliabilitetsanalyse og eksplorativ faktoranalyse for skjemaet Patient Reported Outcomes in Obesity (PROS) $(\mathrm{n}=\mathbf{2 0 4})$.

\begin{tabular}{|lcccc|}
\hline PROS-spørsmål & $\begin{array}{l}\text { Item-total- } \\
\text { korrelasjon }\end{array}$ & $\begin{array}{c}\text { Cronbachs } \\
\text { alfa dersom } \\
\text { ett spørsmål } \\
\text { mangler }\end{array}$ & $\begin{array}{c}\text { Faktor- Kommunalitet } \\
\text { ladning }\end{array}$ \\
\hline $\begin{array}{l}\text { Vanlige fysiske } \\
\text { aktiviteter }\end{array}$ & 0,73 & 0,88 & 0,80 & 0,64 \\
\hline Smerter i kroppen & 0,67 & 0,88 & 0,74 & 0,55 \\
\hline $\begin{array}{l}\text { Diskriminering/ufin } \\
\text { oppførsel }\end{array}$ & 0,60 & 0,89 & 0,70 & 0,49 \\
\hline Søvn & 0,57 & 0,89 & 0,66 & 0,43 \\
\hline Seksualliv & 0,65 & 0,89 & 0,74 & 0,54 \\
\hline Vanlig sosial omgang & 0,72 & 0,88 & 0,81 & 0,65 \\
\hline $\begin{array}{l}\text { Arbeid, skole, daglige } \\
\text { gjøremål }\end{array}$ & 0,75 & 0,88 & 0,83 & 0,69 \\
\hline Selvfølelse & 0,75 & 0,88 & 0,83 & 0,68 \\
\hline
\end{tabular}

${ }^{1}$ Total korrelasjon med egen PROS-skala korrigert for overlapping. Cronbachs alfa for PROStotalskår var 0,9o. Prinsipal komponentanalyse viste at én enkeltfaktor (egenverdi = 4,7) forklarte $58,4 \%$ av variasjonen i skjemaet. Kaiser-Meyer-Olkin-verdi = o,89 og Bartletts sfæretest $<0,001$.

\section{Tabell $_{3}$}

Korrelasjon mellom skjemaene Patient Reported Outcomes in Obesity (PROS), Impact of weight on quality of life questionnaire short-form (IWQOL-Lite) og kroppsmasseindeks (BMI).

\begin{tabular}{|c|c|c|c|c|c|c|c|}
\hline \multirow[b]{2}{*}{ PROS $^{1}$} & \multicolumn{7}{|c|}{ IWQLL-Lite og BMI } \\
\hline & Sumskår & $\begin{array}{c}\text { Fysisk } \\
\text { funksjonsevne }\end{array}$ & Selvfølelse & sualliv & $\begin{array}{l}\text { fentlig } \\
\text { astning }\end{array}$ & Arbeid & BMI \\
\hline Sumskår & $-0,91$ & $-0,88$ & $-0,84$ & $-0,76$ & $-0,77$ & $-0,87$ & 0,60 \\
\hline $\begin{array}{l}\text { Fysisk } \\
\text { aktivitet }\end{array}$ & $-0,75$ & $-0,80$ & $-0,64$ & $-0,63$ & $-0,62$ & $-0,72$ & 0,55 \\
\hline Smerter & $-0,70$ & $-0,71$ & $-0,52$ & $-0,51$ & $-0,52$ & $-0,65$ & 0,39 \\
\hline Diskriminering & $-0,69$ & $-0,62$ & $-0,66$ & $-0,45$ & $-0,70$ & $-0,63$ & 0,46 \\
\hline Søvn & $-0,54$ & $-0,57$ & $-0,49$ & $-0,43$ & $-0,44$ & $-0,54$ & 0,32 \\
\hline Seksualliv & $-0,67$ & $-0,61$ & $-0,59$ & $-0,74$ & $-0,54$ & $-0,62$ & 0,42 \\
\hline $\begin{array}{l}\text { Sosial } \\
\text { omgang }\end{array}$ & $-0,76$ & $-0,70$ & $-0,76$ & $-0,65$ & $-0,68$ & $-0,72$ & 0,56 \\
\hline Arbeid, skole & $-0,76$ & $-0,74$ & $-0,68$ & $-0,57$ & $-0,64$ & $-0,79$ & 0,53 \\
\hline Selvfølelse & $-0,81$ & $-0,68$ & $-0,87$ & $-0,71$ & $-0,69$ & $-0,73$ & 0,50 \\
\hline
\end{tabular}

${ }^{1}$ Pasienttallene for PROS var 204, IWQOL-Lite 158-195 og 200 for kroppsmasseindeks. Pverdier for alle korrelasjoner er < o,oo1.

\section{Tabell 4}


Oversikt over fordeling (\%) i besvarelsene av skjemaet Patient Reported Outcomes in Obesity (PROS) i ikke-operert $(\mathrm{n}=109)$ og operert gruppe $(\mathrm{n}=95)$

\begin{tabular}{|c|c|c|c|c|}
\hline & \multicolumn{2}{|c|}{ Ikke-operert gruppe } & \multicolumn{2}{|c|}{ Operert gruppe } \\
\hline PROS-subskår & $\begin{array}{c}\text { Ikke/mildt } \\
\text { plaget }\end{array}$ & $\begin{array}{c}\text { Moderat/betydelig } \\
\text { plaget }\end{array}$ & $\begin{array}{l}\text { Ikke/mildt } \\
\text { plaget }\end{array}$ & $\begin{array}{c}\text { Moderat/betydelig } \\
\text { plaget }\end{array}$ \\
\hline Fysisk aktivitet & 29,4 & 70,6 & 87,4 & 12,6 \\
\hline Smerter & 27,5 & 72,5 & 68,4 & 31,6 \\
\hline Diskriminering & 66,1 & 33,9 & 97,9 & 2,4 \\
\hline Søvn & 41,3 & 58,7 & 77,9 & 22,1 \\
\hline Seksualliv & 46,8 & 53,2 & 86,3 & 13,7 \\
\hline Sosial omgang & 59,6 & 40,4 & 93,7 & 6,3 \\
\hline Arbeid, skole & 40,4 & 59,6 & 93,7 & 6,3 \\
\hline Selvfølelse & 24,8 & 75,2 & 78,9 & 21,1 \\
\hline
\end{tabular}

\section{Diskusjon}

Man kan stille spørsmål om hvorfor vi utviklet et nytt skjema i stedet for å bruke eksisterende fedmespesifikke skjema som for eksempel Obesity Related Problem Scale (OP) (18), Moorehead-Ardelt Quality of Life Questionnaire II (19) eller IWQOL-Lite (12). IWQOLLite-skjemaet blir regnet som gullstandarden, men inneholder mange utsagn (20) og skårene er vanskelig å regne ut mens man sitter i samtale med pasienten. The MooreheadArdelt Quality of Life Questionnaire II er et kort, kommersielt skjema. Dette begrenser den kliniske bruken. Erfaring tilsier at det er behov for et skjema som er raskt å fylle ut, enkelt å summere og som kan benyttes kostnadsfritt i klinikken. Vi var inspirert av Obesity Related Problem Scale, som vi også har oversatt og validert på norsk (18). Dette er et fedmespesifikt skjema som måler psykososial funksjon (18). I tillegg til psykososial funksjon ønsket vi å samle inn data på fysisk aktivitet, smerter, søvn, diskriminering og selvfølelse, da disse områdene også har betydning for helserelatert livskvalitet (20-24).

Hovedformålet med PROS-skjemaet er at det skal fremme dialogen mellom pasient og kliniker og dermed føre til mer målrettede konsultasjoner. PROS-totalskår er basert på at alle underpunkt er vektet likt, men slik er det ikke alltid på individnivå. I hvilken grad en pasient har plager kan dermed avvike fra totalskåren. Vi anbefaler derfor å spørre pasientene om i hvilken grad de føler seg plaget samlet sett, fra «ikke plaget» til «betydelig plaget». Slik kan man se om totalskåren er noe pasienten kjenner seg igjen i.

PROS-skjemaet måler i hvilken grad vekt eller kroppsform oppleves som plagsom. En begrensning i denne studien er at skjemaet bare er validert $i$ en gruppe pasienter som er kvalifisert for fedmekirurgi. Det er derfor ikke sikkert at PROS-skjemaet er like reliabelt og valid for bruk til pasienter som ikke er kvalifisert for eller ønsker fedmekirurgi. En annen begrensning er at vi ikke fulgte opp pasientene over tid, men brukte et tverrsnittdesign. Dette kan føre til at PROS-skjemaets følsomhet for endring kan være litt usikker. Det er også brukt selvrapportert høyde og vekt, noe som kan medføre unøyaktighet. Det vil bli gjort videre studier med større utvalg for å utforske PROS-skjemaets faktorstruktur.

En styrke ved studien er at det er mange inkluderte pasienter og høy svarprosent fra representative pasienter. I tillegg er PROS-skjemaet sammenlignet med gullstandarden for pasientgruppen, IWQOL-Lite-skjemaet (24). Skjemaet er fritt tilgjengelig for bruk i klinisk praksis og forskning (appendiks 1 ).

\section{Konklusjon}

PROS-skjemaet er et reliabelt og valid skjema for måling av fedmespesifikk livskvalitet. Det kan egne seg for bruk både i klinisk praksis og forskning. Skjemaet viser god validitet $\mathrm{i}$ forhold til IWQOL-Lite-skjemaet og skal være enkelt å tolke for klinikeren. Det er behov for studier der skjemaet blir brukt til å følge pasienter over tid, også i grupper av pasienter med fedme som ikke ønsker kirurgisk behandling. 


\section{HOVEDFUNN}

Det er behov for skjemaer for måling av livskvalitet der svarene enkelt kan vurderes under pasientsamtale

PROS-skjemaet (Patient Reported Outcomes in Obesity) viser seg å være et reliabelt og valid skjema som egner seg for bruk både i klinisk praksis og forskning

\section{LITTERATUR:}

1. Magallares A, Schomerus G. Mental and physical health-related quality of life in obese patients before and after bariatric surgery: a meta-analysis. Psychol Health Med 2015; 20: 165-76. [PubMed][CrossRef]

2. Andersen JR, Karlsen TI, Kolotkin R. Obesity and its impact upon quality of life. I: Mullin G, Cheskin LJ, Matarese LE, red. Integrative Weight Management. New York, NY: Springer, 2014: 225-35.

3. Driscoll S, Gregory DM, Fardy JM et al. Long-term health-related quality of life in bariatric surgery patients: A systematic review and meta-analysis. Obesity (Silver Spring) 2016; 24: 60-70. [PubMed][CrossRef]

4. Andersen JR, Aasprang A, Karlsen TI et al. Health-related quality of life after bariatric surgery: a systematic review of prospective long-term studies. Surg Obes Relat Dis 2015; 11: 466-73.

[PubMed][CrossRef]

5. Thomson L, Sheehan KA, Meaney C et al. Prospective study of psychiatric illness as a predictor of weight loss and health related quality of life one year after bariatric surgery. J Psychosom Res 2016; 86: 7-12. [PubMed][CrossRef]

6. Ghaferi AA, Lindsay-Westphal C. Bariatric surgery-more than just an operation. JAMA Surg 2016; 151: 232-3. [PubMed][CrossRef]

7. Moons P, Budts W, De Geest S. Critique on the conceptualisation of quality of life: a review and evaluation of different conceptual approaches. Int J Nurs Stud 2006; 43: 891-901. [PubMed][CrossRef]

8. Barstad A. Gode liv i Norge. Utredning om måling av befolkningens livskvalitet. Oslo: Helsedirektoratet, 2016.

https://www.helsedirektoratet.no/rapporter/gode-liv-i-norge-utredning-om-maling-av-befolkningenslivskvalitet/Gode\%2oliv\%2oi\%2oNorge\%20\%E2\%80\%93\%2oUtredning\%20om\%20m\%C3\%A5ling\%2oav\%2ob efolkningens\%2olivskvalitet.pdf/_/attachment/inline/4d212043-e2a4-4904a36o-94bfd977ed9a:51d6f261364996e6656a4e0564fb9bc967b4ecfo/Gode\%2oliv\%2oi\%2oNorge.pdf Lest 22.2.2019.

9. Kolotkin RL, Meter K, Williams GR. Quality of life and obesity. Obes Rev 2001; 2: 219-29. [PubMed][CrossRef]

10. Karlsson J, Taft C, Sjöström L et al. Psychosocial functioning in the obese before and after weight reduction: construct validity and responsiveness of the Obesity-related Problems scale. Int J Obes Relat Metab Disord 2003; 27: 617-30. [PubMed][CrossRef]

11. Kolotkin RL, Andersen JR. A systematic review of reviews: exploring the relationship between obesity, weight loss and health-related quality of life. Clin Obes 2017; 7: 273-89. [PubMed][CrossRef]

12. Kolotkin RL, Crosby RD, Kosloski KD et al. Development of a brief measure to assess quality of life in obesity. Obes Res 2001; 9:102-11. [PubMed][CrossRef]

13. Aasprang A, Andersen JR, Våge V et al. Reliability and validity of the Norwegian version of Impact of Weight on Quality of Life questionnaire. Obes Facts 2016; 9: 222.

14. Cohen J. Statistical power analysis for the behavioral sciences. 2. utg. Hillsdale, MI: Lawrence Erlbaum Associates, 1988.

15. Carlson KD, Herdman AO. Understanding the impact of convergent validity on research results. Organ Res Methods 2012; 15: 17-32. [CrossRef]

16. Staquet MJHR, Fayers PM. Quality of life assessment in clinical trials. Oxford: Oxford Press, 1998.

17. Wyrwich KW, Tierney WM, Wolinsky FD. Further evidence supporting an SEM-based criterion for 
identifying meaningful intra-individual changes in health-related quality of life. J Clin Epidemiol 1999; 52: 861-73. [PubMed][CrossRef]

18. Aasprang A, Andersen JR, Våge V et al. Psychosocial functioning before and after surgical treatment for morbid obesity: reliability and validation of the Norwegian version of obesity-related problem scale. Peer] 2015; 3: e1275. [PubMed][CrossRef]

19. Moorehead MK, Ardelt-Gattinger E, Lechner H et al. The validation of the Moorehead-Ardelt Quality of Life Questionnaire II. Obes Surg 2003; 13: 684-92. [PubMed][CrossRef]

20. Vincent HK, Heywood K, Connelly J et al. Obesity and weight loss in the treatment and prevention of osteoarthritis. PM R 2012; 4 (suppl): S59-67. [PubMed][CrossRef]

21. Hunger JM, Major B. Weight stigma mediates the association between BMI and self-reported health. Health Psychol 2015;34:172-5. [PubMed][CrossRef]

22. Hansen BH, Kolle E, Dyrstad SM et al. Accelerometer-determined physical activity in adults and older people. Med Sci Sports Exerc 2012; 44: 266-72. [PubMed][CrossRef]

23. Shah N, Roux F. The relationship of obesity and obstructive sleep apnea. Clin Chest Med 2009; 30: 455-65, vii. [PubMed][CrossRef]

24. Natvik E, Gjengedal E, Råheim M. Totally changed, yet still the same: patients' lived experiences 5 years beyond bariatric surgery. Qual Health Res 2013; 23: 1202-14. [PubMed][CrossRef]

Publisert: 19. august 2019. Tidsskr Nor Legeforen. DOI: 10.4045/tidsskr.18.0493

Mottatt 11.6.2018, første revisjon innsendt 15.11.2018, godkjent 22.2.2019.

(C) Tidsskrift for Den norske legeforening 2020. Lastet ned fra tidsskriftet.no 